\title{
Aspectos generales sobre la inejecución de sentencias del Tribunal Constitucional
}

\section{Jose Victor Garcia Yzaguirre}

Alumno del Octavo Ciclo de la Facultad de

Derecho de la Universidad de Lima.

Ganador del Concurso de Redacción de Artículos de ADVOCATUS ${ }^{(*)}$

\section{SUMARIO:}

I. ¿Sobre qué discutimos?

II. Las sentencias del Tribunal Constitucional y aspectos dogmáticos relevantes a su ejecución:

1. Categorías, principios y derechos de la ejecución de sentencias;

2. La fase de ejecución frustrada.

III. Mecanismos para garantizar el cumplimiento de sentencias en el marco normativo nacional.

IV. Medidas posibles para fortalecer la efectividad:

1. Referente imprescindible: la Corte Interamericana y la ejecución de sus sentencias.

v. Reflexión Final.

(*) El Jurado Calificador estuvo conformado por los doctores Marco Antonio Ortega Piana, Jorge Bravo Cucci y Ronald Cárdenás Kreñz. ÁDVÓCATUS lés agradece especialmente por su valiosa colaboración. 


\section{I. ¿SOBRE QUÉ DISCUTIMOS?}

El propósito del proceso fue en sus orígenes y es en la actualidad, en esencia, generar orden y justicia en la sociedad al tener el fin de sustituir a la autotutela. Para contrarrestar la naturaleza competitiva del hombre, su ingenio conservativo de sí mismo y su condicionante indispensable para su existencia que es la sociedad, lo llevó a despojar del uso de la fuerza personal al individuo y concentrarlo en una entidad organizadora, administradora y distribuidora. Con el nacimiento del Estado nace la necesidad de parametrar la interacción entre los sujetos para viabilizar, hacer oportuna y no contraproducente la cooperación humana.

Esta idea resume con gran injusticia el gran acontecimiento que fue el nacimiento de la jurisdicción. En la necesidad de resolver los conflictos entre los individuos y de resolver las incertidumbres jurídicamente relevantes, debe aparecer entre las partes un tercero legitimado y desinteresado en la causa a resolver. Es así que la jurisdicción surge como actividad de impartir justicia concentrada de forma unitaria, por evolución histórica, en el Poder Judicial del Estado. Función que deviene en un deber del funcionario estatal y del Poder, pues será su decisión, su concepto de lo justo jurídicamente sustentado, el que prevalezca sobre la sociedad y tenga observación forzosa.

El ejercicio de la jurisdicción aparece ante el requerimiento de partes que discuten por un interés social con relevancia jurídica en el que el Estado interviene como tercero imparcial que emplea la ley dictada por la voluntad de la nación representada para determinar la resolución del caso. Dentro de este concepto se encierran dos órdenes de facultades: la decisión, ejecución, coerción y documentación. La decisión concierne a la declaración de resolución del conflicto, de ejecución en cuando a que es capaz de cumplir sus propios mandatos, coerción referida a la capacidad de uso de la fuerza para la ejecución y documentación entendida como el sustento permanente de la realización de actos jurisdiccionales.' Dicho lo previo, propongo nos cuestionemos, ¿qué sería del proceso si la resolución del conflicto por parte del juez existiese y fuera acorde a derecho, no se ejecutase? Es decir, como personas, ¿en qué nos afecta que no se ejecuten decisiones jurisdiccionales?

Es nuestro contexto, existen quienes observan una significativa renuencia al acatamiento de las sentencias del Tribunal Constitucional (TC), generándose así un ambiente marcado por la inejecución de sus fallos. ${ }^{2}$ Esto en concreto significa una total vulneración de los derechos fundamentales de quienes recurren a la administración de justicia, así como a todos los miembros de la sociedad, en tanto, pertenecientes y contribuyentes a la sociedad que depende de la institucionalidad jurisdiccional para poder realizarse gregariamente. Teniendo en cuenta el carácter especial de la jurisprudencia del TC, en tanto, su fuero ve procesos extraordinarios de defensa de la persona y de sus derechos fundamentales es, en efecto, un incumplimiento de parte de una sentencia que requiera cumplimiento, significa un daño absoluto y superlativo al derecho de tutela procesal efectiva y una inexistencia de cosa juzgada material que culmina siendo un sintoma de autodestrucción del sistema ${ }^{3}$ o por lo menos una muestra del fracaso de este.

1 GARCIA TOMA, Víctor, Los Derechos Fundamentales en el Perú, Jurista Editores, Lima, p. 611.

2 CANALES, Carolina, Eficacia y cumplimiento de las sentencias del Tribunal Constitucional. En: Gaceta Constitucional Gaceta Jurídica, Tomo 4, Lima, Abril, 2008, p. 47. Posición que, evidentemente, que no es pacifica. En sentido contrario, GARCIA TOMA, Victor, Algunos alcances sobre la labor del Tribunal Constitucional. En: Revista Archivo Procesal, editada por alumnos de la Universidad de Lima, No. 3 año 2008, p. 38.

3 Siguiendo la expresión de la Corte Constitucional de Colombia en su sentencia T-554/92 M.P. CIFUENTES MUÑOZ, Eduardo: "el sistema jurídico tiene previstos diversos mecanismos para impedir su autodestrucción. Uno de ellos es el derecho fundamental al cumplimiento de las sentencias comprendido en el núcleo esencial del derecho a un debido proceso publico sin dilaciones injustificadas". CANALES, Carolina, Ob. Cit., p. 18. 
Conforme se desarrolle el presente, trataremos de analizar los supuestos frecuentes de las inejecuciones que son:

- El juez de ejecución no cumple con ejecutar la sentencia.

- La parte no ejecuta la sentencia.

- El Freno de la ejecución por medio de amparos.

\section{LAS SENTENCIAS DEL TRIBUNAL CONSTITUCIONAL Y ASPECTOS DOGMÁ- TICOS RELEVANTES A LA EJECUCION}

Las sentencias del TC son las que producen un mayor impacto en la sociedad. Sus decisiones contienen las siguientes categorías ${ }^{4}$ : cosa juzgada, vinculación a los poderes públicos y fuerza de ley.

La cosa juzgada constitucional supone una comprobación que el TC se comporta de igual forma que un Tribunal regular, es decir, es un órgano que también imparte justicia y se pronuncia casuísticamente. Las características de esta categoría en particular son tratadas en el siguiente capítulo.

La vinculación a todos los poderes públicos es un concepto que contiene la idea de que las decisiones constitucionales escapan al caso concreto y son capaces de forzar sus aplicaciones no solo por las partes sino que tienen efecto erga omnes.

En breve, lo que se pretende argumentar es que las sentencias constitucionales no solo obligan a los litigantes sino que el poder vinculante llega a todos los tribunales y autoridades, debiendo estos asumir ciertos razonamientos, en tanto, deben tomar a cierta ratio decidendi $i^{5}$, como sustento base e ineludible para actuar, efecto que la doctrina alemana llama tragende grande y nosotros legislación positiva. Esto porque "vincular la conducta futura a los órganos y personas que resulten afectados por la decisión constitucional, evitando que comportamientos declarados constitucionales puedan ser de nuevo por ellos reiterados o marcándoles con precisión cuales son los caminos por los que su actuación puede discurrir en el marco de la constitución".

La categoría de fuerza de ley se refiere a ser un reforzamiento de la vinculación de las sentencias. Este elemento extiende los efectos ya no solo a los organismos y autoridades estatales, sino que extiende la orilla aún más allá de las personas jurídicas y naturales, las cuales están en posibilidad de emplear las decisiones para sus pretensiones. No debemos confundir las consecuencias entre la fuerza de ley y la vinculación, si bien recorren un mismo caudal, tienen un impacto y propósito distinto. Los alemanes Ilaman a esta característica gesetzesahnlichkeit, que significa "semejanza de ley". Efectivamente, una sentencia no es una ley en sentido formal ni material, pero comparte con lo normativo en ser fuente de derecho y en que tiene una vinculación a favor y en contra de todos. Como afirma el TC sobre la jurisprudencia como fuente de derecho a pronunciado que "la jurisprudencia es una fuente de derecho que también tiene un fundamento constitucional a través de los órganos jurisdiccionales que la producen. Asimismo, que la labor interpretativa que realizan todos los jueces, inherente a tal función, es la razón de ser de la actividad jurisdiccional, en sede constitucional u ordinaria, y que tiene su fundamento en el principio de independencia consagrado por la Constitución en sus artículos 139, inciso 2 (Poder

4 Para la elaboración de los párrafos relevantes se sigue la doctrina del español estudioso del derecho constitucional alemán, BOCANEGRA SIERRA, Raúl, de su libro El Valor de las Sentencias del Tribunal Constitucional de la editorial Instituto de Estudios de Administración Local.

5 Son las razones y motivos por las cuales se sustenta un fallo, en breve, resultan ser los análisis doctrinarios propios del fuero constitucional. La ratio que es vinculante, es expresamente declarada en sentencia.

6 BOCANEGRA, Raúl, El Valor de las Sentencias del Tribunal Constitucional, Instituto de Estudios de Administración Local, Madrid, p. 64. 
Judicial) y 201 (Tribunal Constitucional). Sin la interpretación la actividad de los jueces estaría condenada al fracaso, pues la Constitución y la ley no pueden prever todos los casos posibles que presenta la realidad según cada época (...) De ahí que todo acto de los poderes públicos $\mathrm{u}$ órganos constitucionales que pretenda restringir dicha función interpretativa no solo es uno que priva a los órganos jurisdiccionales de su función, sino que es inconstitucional (...) Pretender limitar las funciones inherentes del Tribunal Constitucional sería como condenarlo a la inacción por cumplir su deber".' Es en este sentido que somos de la idea que presentar obstáculos a la ejecución de sentencias, ser renuente a ejecutar o no presentar las medidas pertinentes para asegurar o facilitar la misma deben considerarse como limitaciones de facto a las funciones del TC.

Las sentencias del TC tienen el propósito de ser el control de constitucionalidad de las leyes y ser la defensa extraordinaria de los derechos fundamentales. Son, como expresa el propio fuero, "en buena cuenta, constitución viviente de la sociedad plural". En efecto, la Norma Fundamental no solo actúa como paradigma normativo del Ordenamiento Jurídico interno, sino que también tiene acción directa sobre la sociedad por medio de sentencias protectoras de derechos y de control de la constitucionalidad, las cuales, además de resolver controversias, van modernizando el contenido material de lo escrito por medio de la argumentación jurídica interpretativa.

Como bien a concluido Garrorena Morales, una sentencia debe ser entendida "como acto procesal, como actividad dirigida a la interpretación e integración creadora del Derecho, y como decisión política, respondiendo a los principios de congruencia, motivación, decisión colegial y eficacia". Siguiendo esta línea, un efecto colateral a un proceso constitucional es la construcción de ciudadanía, en tanto, genera un efecto concientizador en la población de la existencia, validez y eficacia de sus derechos, es decir, se contribuye a la creación de un Estado democrático no solo por medio de invenciones jurídicas, también lo hace por medio de construcción ideológica.

Raúl Bocanegra nos aporta para encontrar el significado de una sentencia constitucional que "(un) proceso constitucional no es sino un autocontrol del Estado sobe la juridicidad de sus propias manifestaciones soberanas. La idea es, en efecto, que el Estado habla por muchas bocas', no puede sin contradecirse a si mismo, manifestarse mas que en un único sentido y atribución a un órgano constitucional la determinación del alcance del pensamiento del Estado, deben los demás órganos acomodarse sin mas a estas manifestaciones ser vinculados a las mismas (...) porque la propia cualidad de la relación, la unidad del Estado y del Poder del Estado, en este sentido consecuencia de la naturaleza de todos los demás órganos a las manifestaciones del Tribunal Constitucional y la vinculación de los órganos del Estado al contenido de sus sentencias".10 Desviándonos del criterio jurídico, un fallo constitucional, por su naturaleza jurídica y política, puede ser interpretada como un acto directo del Estado concretizado en una entidad para expresarse razonadamente sobre las acciones del Gobierno. Es decir, el Ser reinventa constantemente al Ente.

Cabe mencionar que las sentencias constitucionales son mas cercanas procesalmente al tipo de sentencia de condena de ejecución forzosa, pero este no es el enfoque de mira a tener para un análisis de este tipo, pues, como dicta la doctrina del TC, "la ejecutabilidad de la sentencia constitucional no se desprende de la "naturaleza"

7 Sentencia del Tribunal Constitucional en Expediente No. 00047-2004-Al.

8 Sentencia del Tribunal Constitucional en Expediente No. 0048-2004-PI.

9 Citado por CANALES, Carolina, Ob. Cit., p. 53.

10 BOCANEGRA, Raúl, Ob. Cit., p. 57. 
de condena o de lo que ella represente, sino de la posición que le otorga el sistema constitucional a las decisiones del máximo tribunal jurisdiccional del pais".".Si nos preguntamos por qué se señala que es de tipo de condena, referida fuente nos responde que las sentencias "en los procesos para la tutela de los derechos fundamentales serian, prima facie, sentencias de condena que contienen un mandato ejecutivo $y$, por tanto, se trataría de decisiones que pueden ser objeto de ejecución forzosa", esto porque "la orden del juez constitucional está encaminada, como lo establece el artículo 1 del Código Procesal Constitucional, $a$ "(...) reponer las cosas al estado anterior a la violación o amenaza de violación de un derecho constitucional", o,en todo caso, a obligar a la autoridad o poder público a cumplir "un mandato legal o un acto administrativo". ${ }^{12}$

A continuación se procede a explicar primero las categorías y principios constitucionales relevantes, tratando, por lo menos, de ensayar un atisbo de la magnitud real de su violación ${ }^{13} y$ encontrar los puntos débiles del sistema.

\section{Categorías, Principios y Derechos de la ejecución de sentencias}

La denominación categoría constitucional alude a los "géneros conceptuales que subsumen y agrupan a una pluralidad de nociones afines $y$ que permiten regular una situación jurídica de manera sistemática, lógica y armónica que la Constitución persigue alcanzar en el seno de la convivencia dentro de una sociedad política. Estas reúnen y ordenan doctrinariamente una serie de ideas y conceptos adscritos a una espe- cifica materia". ${ }^{14}$ En este universo está comprendida la tutela procesal efectiva ${ }^{15}$, compuesta esta de las categorías de tutela jurisdiccional y el debido proceso.

El debido proceso esta compuesto por el derecho al juez natural, al derecho de defensa, el derecho a la instancia plural, el derecho a la cosa juzgada, el derecho al plazo razonable, la motivación escrita de las resoluciones, etc. La premisa básica y esencial para la obtención de un proceso justo y válido es la observancia fiel y constante a este derecho. Lo dicta la razón de ser del procedimiento y la necesidad de los administrados por un mecanismo real y legitimo para la resolución de sus controversias. Sin embargo, es de notar que los alcances y propósitos de la dinámica del debido proceso, si bien es presupuesto indispensable para llegar a una sentencia, sus fronteras ni sus mecanismos son burlados, es decir, mediante una inejecución no se vulnera directamente el debido proceso.

Lo que se pretende analizar, para comprender el grado de afectación que genera a los derechos de las personas una inejecución, es el derecho a la tutela jurisdiccional efectiva. Este es un "derecho constitucional de naturaleza procesal en virtud del cual toda persona o sujeto justiciable puede acceder a los órganos jurisdiccionales independientemente del tipo de pretensión formulada de la eventual legitimidad que pueda o no acompañarle a su petitorio (...) la tutela judicial efectiva permite también que lo que ha sido decidido judicialmente, mediante una sentencia, resulte eficazmente cumplido. En otras palabras, con la tutela judicial efectiva

11 Sentencia del Tribunal Constitucional en el Expediente No. 4119-2005-AA.

12 Ibidem.

13 Las invenciones jurídicas en materia de derechos fundamentales, en especial cuando a de tratarse de tutela jurisdiccional, son diseñadas con miras a la preponderancia del respeto por la dignidad del hombre y por la consolidación de los valores que pretende concretar un Estado Social y Democrático derecho. Tratar de comprender el alcance total de una afectación a estas que conlleva a un daño a un derecho fundamental o a un bien jurídico tutelado, esta fuera de probabilidades de éxito.

14 GARCIA TOMA, Víctor, Los Derechos Fundamentales en el Perú, Ob. Cit., p. 607.

15 Derecho no enumerado, creado no en contenido pero si en nomenclatura por vía jurisprudencial en la sentencia del Tribunal Constitucional en el Expediente No. 3283-2003-AA. 
no solo se persigue asegurar la participación o acceso del justiciable a los diversos mecanismos (procesos) que habilita el ordenamiento dentro de los supuestos establecidos para cada tipo de pretensión, sino que se busca garantizar que, tras el resultado obtenido, pueda verse este ultimo materializado con una mínima y sensata dosis de eficacia". ${ }^{16}$

Tenemos que esta categoría está compuesta por el acceso a la jurisdicción, derecho a obtener una resolución firme sobre la pretensión y el derecho a la ejecución de las sentencias firmes. Es así como reducimos nuestro espectro investigativo: el derecho a la ejecución de sentencias.

Como recalca Francisco Chamorro, la efectividad de las sentencias "es algo consustancial al derecho de tutela judicial, puesto que, como ha reiterado el TC, una tutela que no fuera efectiva, por definición no sería tutela. De nada servirian al ciudadano unas excelentes resoluciones judiciales que no se llevaran a la práctica". ${ }^{17}$ Lo citado nos devuelve al inicio del presente texto, el propósito y la lógica de desarrollar un conjunto articulado y coherente de actos destinados a lograr la actuación de un tercero desinteresado en una controversia entre situaciones sociales con relevancia jurídica radica en dos ejes: la obtención de una decisión basada en el derecho, la justicia y la conveniencia social con consecuencia materializada.

La efectividad consiste en que el "ciudadano tenga acceso real y no formal o teórico a la jurisdicción, al proceso y al recurso; que pueda defenderse real y no retóricamente, que no se le pongan impedimentos irrazonables a ello. Efectividad quiere decir que la persona afectada por un juicio sea llamada al mismo, efectividad quiere decir que no se hurte al ciudadano una resolución al amparo de formalismos exagerados; efectividad quiere decir que la resolución decida realmente el problema planteado".18 En pocas palabras, efectividad es el tránsito de lo decido por un funcionario del Estado a la realidad social, es decir, una forma que modifica un fondo considerado adverso.

Siguiendo la misma doctrina, divide la efectividad en cuatro tipos siguiendo un criterio de nivel de formalidad ${ }^{19}:$ 1) Garantiza la obtención de una respuesta del órgano jurisdiccional; 2) La respuesta del órgano jurisdiccional debe realmente resolver el problema planteado; 3 ) Garantiza que la solución al problema planteado sea razonable y extraída del ordenamiento jurídico; 4) Asegura la ejecución de la decisión tomada.

Como es evidente, existe un reduccionismo en esta doctrina en cada nivel propuesto de lo que es el derecho a tutela jurisdiccional, siendo únicamente en el cuarto tipo una real dimensión del derecho. Volveremos sobre este punto al analizar el efecto negativo de la formalidad exhaustiva sobre la resolución de conflictos jurídicos.

El derecho a la ejecución de sentencias esta regulado constitucionalmente en el artículo 139 inciso 2 que reza: "Son principios y derechos de la función jurisidiccional: La independencia en el ejercicio de la función jurisdiccional. Ninguna autoridad puede avocarse a causas pendientes ante el órgano jurisdiccional ni interferir en el ejercicio de sus funciones. Tampoco puede dejar sin efecto resoluciones que han pasado en autoridad de cosa juzgada, ni cortar procedimientos en trámite, ni modificar sentencias ni retardar su ejecución. Estas disposiciones no afectan el derecho de gracia ni la facultad de investigación del Congreso, cuyo ejercicio no debe, sin embargo, interferir en el procedimiento jurisdiccional ni surte efecto jurisdiccional alguno".

16 Sentencia del Tribunal Constitucional en el Expediente No. 763-2005-PA.

17 CHAMORRO BERNAL, Francisco, La Tutela Judicial Efectiva, Bosch, Barcelona, p. 276.

18 CHAMORRO, Francisco, Ob. Cit., p. 276.

19 CHAMORRO, Francisco, Ob. Cit., p. 278. 
De inmediato es de advertirse los aspectos prácticos de la ejecución: aspecto estático y un aspecto dinámico.

El aspecto estático debe entenderse como el deber los jueces y tribunales de llevar a cabo lo decidido por estos o por un fuero superior a ellos mismos. Es decir, la efectividad comprendida como la función de la magistratura de connotar de realidad, de dar "vida" en forma y fondo a lo decidido jurisdiccionalmente. Como deber, existe sanción al incumplimiento que son las multas e incluso la destitución del omitente responsable. ${ }^{20}$ Como sentenció el TC, este aspecto "exige un particular tipo de actuación. $Y$ es que si el derecho a la ejecución de las resoluciones judiciales garantiza que lo decidido en una sentencia o en una resolución judicial sea cumplido, es claro que quienes las dictan, o quienes resulten responsables de ejecutarlas, tienen la obligación de adoptar, según las normas y procedimientos aplicables -y con independencia de que la resolución a ejecutar haya de ser cumplida por un ente público o no-las medidas necesarias yoportunas para su estricto cumplimiento".21

El aspecto dinámico del derecho a ejecución de sentencias actúa plenamente ante la existencia de un funcionario renuente a hacer eficaz una sentencia firme. EI TC español define este presupuesto procesal tratándolo como una persistencia en la inacción, pese a que el afectado en sus intereses.legítimos le ha recordado que existe un mandato en acto administrativo aun no cumplido. ${ }^{22}$

Profundizando la temática Elvito Rodríguez escribe que es el "proceso de pretensión insatisfecha, no busca la declaración de la existencia de la relación jurídica sino busca la actuación de la relación jurídica, es decir, busca la adecuación de lo que es a lo que debe ser."23 Este autor cita a Véscovi, quien propone que "luego del proceso de conocimiento, si corresponde (porque hay una condena y no se cumple) viene la etapa de ejecución, que es un nuevo proceso, en el que se ejecuta lo juzgado. El proceso de ejecuciones puede no estar precedido de otro de conocimiento".24 Consideramos que debemos disentir del fondo de este razonamiento. $\mathrm{Si}$ bien es cierto, al dictarse una sentencia el interés procesal termina poniéndose fin a lo que debiera ser la gesta entre argumentos y posturas jurídicas, pero no hemos de perder de vista lo fundamental: el porqué del litigio. El proceso no termina cuando es satisfecho el interés procesal sino cuando es materializado el interés material de la pretensión. Sostener que es otro proceso, solo es admisible si es que se refiere a que es una fase del mismo, como sub proceso del proceso, más no si contiene la connotación de que es uno particular. Volveré sobre el punto al exponer sobre la afectación a la cosa juzgada material y la inejecución como supuesto de autodestrucción del sistema. Por lo pronto, es de apuntar que existe una doble victimización ${ }^{25}$ de los particulares al haber una inejecución que no solo daña la dignidad de la

20 El Anteproyecto del Código Procesal Constitucional incluía en el artículo 22 la figura de prisión civil efectiva por incumplimiento, medida existente en el common law en la 'Contempt of Court' que ha devenido en el tiempo en ser eficiente en resultados.

21 Sentencia del Tribunal Constitucional en el Expediente No. 015-2001-Al y Éxp. 004-2002-Al (acumulados).

22 Sentencia del Tribunal Constitucional en el Expediente No. 191-2003-AC.

23 RODRIGUEZ DOMINGUEZ, Elvito, Manual de Derecho Procesal Constitucional, Editorial Grijley, Lima, p. 102, citando al libro de CARNELUTTI, Francisco, instituciones del proceso civil, Editorial UTEHA, pp. 76 y 77.

24 Ibidem.

25 Como parte en un proceso el ciudadano bien puede haber sido un agredido que buscaba que la realidad vuelva a ser como era antes de que el fuese dañado con una indemnización que trate de aliviar las afectaciones sufridas o bien un inculpado indebidamente que fue sujeto de una acusación e investigación que requirieron costos para defenderse. Luego de esta situación, indeseada para la parte que sea, uno es nuevamente agredido por la entidad jurisdiccional que nos ofrece lo que tanto se persiguió, pero que no se esfuerza en dárnoslo, resulta el único perturbado quien justamente era al que se buscaba amparar. 
persona sino la institucionalidad jurisidiccional en sí misma.

Cabe citar la doctrina del TC sobre este aspecto la que expresa que "el derecho a la ejecución de las sentencias como componente del derecho a la tutela jurisdiccional efectiva supone la posibilidad de que la tutela ofrecida por el juez constitucional opere generando consecuencias fácticas en el ámbito de los derechos fundamentales de las personas. De ahi que sea acertado afirmar que la tutela jurisdiccional que no es efectiva no es tutela. Y es que la pronta y debida ejecución de las sentencias permite además dar efectividad al Estado democrático de Derecho, que implica, entre otras cosas, la sujeción de los ciudadanos y de la Administración Pública a lordenamiento jurídico y a las decisiones que adopta la jurisdicción, no sólo juzgando sino también ejecutando lo juzgado. Asi pues, será inconstitucional todo aquel acto que prorrogue en forma indebida e indefinida el cumplimiento de las sentencias." 26

En efecto, a parecer propio, este derecho despliega su radio de acción sobre la promoción de la efectividad de la tutela jurisdiccional y las medidas favorables a la materialización de esta. Lo primero tiene raíz en el aspecto estático, pues pretende asegurar el cumplimento de un deber. Es imperativo por parte de los Poderes del Estado generar mecanismos y estructuras propicias para limitar las posibilidades de la inejecución, y para cuando estas ocurran, existan vías para la reparación del daño que causen. Lucidamente el TC español sentenció "no puede pesar sobre los ciudadanos un resultado gravoso para sus derechos fundamentales, que se originó en la falta de la diligencia debida por los poderes públicos en garantía de su plena efectividad".27

El legislativo ha de crear normas lo suficientemente eficientes y socialmente viables además de relevantes para hacer que el proceso no sea una mera ficción potente, pero infértil, sino que sea un medio real para la promoción de derechos. Lo judicial siempre debiera considerar la eliminación constante y sistemática de toda patología existente amenazante de la ejecución. $Y$ finalmente, que el ejecutivo no sea ajeno y que este genere"medios estructurales para que la administración de justicia pueda ser eficaz, evitando que sus carencias repercutan en los justiciable, puesto que en el deber de garantizar la justicia va implicita la dotación a los órganos judiciales de los necesarios medios personales y materiales".28

En cuanto a los medios favorables serán abordados después de encontrar el momento patológico a fin de adecuar el remedio a la enfermedad.

\section{La Fase de Ejecución Frustrada}

La ejecución viene a ser aplicada a una sentencia posterior al agotamiento de los recursos de impugnación posibles o tras ser consentida. Se requiere, la existencia de una resolución fundada con mandato de ejecución que debe ser cumplida en sus propios términos, es decir, no puede decirse que hay ejecución hasta que se hayan cumplido todos los puntos del fallo dado.

Entramos a una nueva arista del problema, el problema de la inejecución no se reduce al incumplimiento total sino también al mero cumplimiento parcial de un fallo constitucional. Como bien se pronuncia la doctrina nacional "el cumplimiento de lo previsto en el fallo y constituye, junto al derecho del favorecido a exigir el cumplimiento total e inalterado, el del condenado a que no se desvirtúe, se amplie o se sustituya por otro".29 Debe prevalecer siempre una identidad entre lo

26 Sentencia del Tribunal Constitucional en el Expediente No. 04909-2007-HC.

27 Sentencia del Tribunal Constitucional Español en el Expediente No. 73/1986 de 3 junio, BOE 17/6/86, JC XV.

28 CHAMORRO, Francisco, Ob. Cit., p. 280.

29 FERNANDEZ PACHECO MARTINEZ, Teresa, La ejecución de las sentencias en sus propios términos y el cumplimiento equivalente, Tecnos, Lima, p. 26. 
que se ejecute con lo ordenado jurisdiccionalmente, sin modificación alguna. Sobre este punto la Comisión que elaboró el Código Procesal Constitucional se pronuncio señalando que "las decisiones judiciales se cumplan en sus propios términos, esto es, que contrariando tradiciones seculares, no se permita que la actuación de una sentencia se substituya por su valor patrimonial, cuyo pago viene a ser una suerte de equivalente monetario de la decisión ordenada". ${ }^{30}$

El cumplimiento tardío, por otra parte, es también una forma de vulneración del derecho a la efectividad de las resoluciones. Para la protección de los derechos fundamentales de la persona, las dilaciones pueden resultar tener el mismo efecto que una inejecución. Además a este se le agrava, pues para el beneficiario le va posiblemente significar la existencia de una obligación a actuar y que no haya obediencia de esta cuando debiera ser, lo cual le sigue causando perjuicio, que se le agrega frustración y un mayor peso a la vulneración. Sobre esto, el TC español ha expresado que "el derecho a exigir que las sentencias se cumplan sin dilaciones indebidas, si bien no se confunde con el derecho a su ejecución, se encuentra en intima relación con el mismo, pues es claro que el retraso injustificado en la adopción de las medidas afecta en el tiempo a la efectividad del derecho fundamental". ${ }^{31}$ Asimismo, sobre el plazo razonable para el cumplimiento de sentencias, nuestro Supremo Intérprete ha expresado que "no sólo debe entenderse referido al trámite que existe entre la presentación de una demanda y la decisión sobre el fondo, sino que resulta indispensable que dicho concepto se entienda también como una exigencia para lograr la efectividad del pronunciamiento judicial en un plazo que no debe exceder lo que la naturaleza del caso y sus naturales complicaciones de cumplimiento ameriten (...) toda dilación indebida que retarde innecesariamente el cumplimiento pleno de lo que mediante una sentencia judicial firme se ha ordenado, debe entenderse como vulneratoria del derecho fundamental a la tutela judicial efectiva que la constitución reconoce". ${ }^{32}$

Visto esto, es claro que estamos ante una real ejecución cuando materializa lo dictado por un órgano jurisdiccional en sentencia firme en todos sus extremos dentro del plazo debido. De no existir esta, estaríamos considerando a los derechos fundamentales de las personas, a los mandatos imperativos de la Constitución y a los fines del proceso a ser meros enunciativos líricos. Los encargados de llevar a concreción los mandatos estarían (y lo están), mancillando y denigrando aquello que nos permite asegurar nuestra libertad.

De igual forma, significa una vulneración a la ejecución de sentencias, las que se llevan a cabo de forma fraudulenta o simulada, pues en real cuenta, son un incumplimiento material de lo ordenado. Asimismo lo es cuando el juez de ejecución, debiendo establecer medidas para ejecutar, no las realiza se perjudica gravemente la ejecución misma. Es así que llegamos a una nueva arista de la problemática: el derecho a ejecución de sentencias involucra la remoción de obstáculos tanto previos como posteriores al fallo que puedan o estén afectando seriamente o generando dilaciones indebidas a la ejecución misma. En efecto, la naturaleza misma de un cumplimiento es de carácter sumario, solo así es interpretable al comprender al interpretar este derecho junto a los demás pertenecientes a la categoría jurídica de tutela procesal efectiva y al leer teleológicamente las razones y propósitos de un proceso de tutela de derechos:

Esta posición fue también adoptada por el TC cuando exige a los jueces la remoción de obstáculos para la ejecución de sentencias. Veamos "(...) la autoridad jurisdiccional en la etapa de ejecución de sentencias constituye un

30 CASTILLO CORDOVA, Luis, Comentarios al Código Procesal Constitucional, Palestra, Tomo 1, Lima, p. 439.

31 Sentencia del Tribunal Constitucional Español 167/1987, citando la 125/1987.

32 Sentencia del Tribunal Constitucional en el Expediente No. 04080-2004-AC. 
elemento fundamental e imprescindible en el logro de una efectiva tutela jurisdiccional, siendo de especial relevancia para el interés público, dado que el Estado de Derecho no puede existir cuando no es posible alcanzar la justicia a través de los órganos establecidos para tal efecto. Para ello, la autoridad jurisdiccional deberá realizar todas aquellas acciones que tiendan a que los justiciables sean repuestos en sus derechos (...) reaccionando frente a posteriores actuaciones o comportamientos que debiliten el contenido material de sus decisiones, pues sólo asi se podrán satisfacer los derechos de quienes han vencido en juicio, sin obligarles a asumir la carga de nuevos procesos". ${ }^{33}$

Conociendo como se vulnera una ejecución, veamos ahora el instante en el que esta nace. El artículo 148 del Reglamento Normativo del TC señala que los efectos jurídicos de una sentencia constitucional comienzan al día siguiente de su notificación, o en su defecto de su publicación, en tanto reúna todos los requisitos formales y materiales. ${ }^{34}$ Dado este supuesto, siguiendo el principio de ejecutoriedad, dentro de plazo breve. Expresamente, el artículo 59 del Código Procesal Constitucional establece que declarada fundada la demanda, esta debe ser cumplida dentro de los dos días siguientes de notificada. Como excepción, duplica el plazo para las omisiones. Es, entonces, la lógica de nuestra ejecución que sea inmediata a carga del juez.
Entendido cómo y cuándo se vulnera la ejecución, permítaseme abordar un nuevo aspecto a analizar sobre la afectación por incumplimiento a la fase de ejecución del proceso. Hemos de comprender una inejecución como un intento de perpeturización del daño a los derechos fundamentales y a la Constitución.

Y es que, de fracasar la legalidad como medio para la preservación de los derechos y la obtención de justicia en caso de perjuicio a estos, ¿quién nos ampara?

Para sustentar esta premisa, hay que partir del análisis a la naturaleza de la cosa juzgada ${ }^{35}$ constitucional: esta en sí misma reafirma los principios de constitucionalidad y de eficacia de la actividad jurisdiccional, en tanto "mediante una sentencia compatible con el orden objetivo de valores, principios y normas constitucionales, así como con la jurisprudencia y precedentes vinculantes de la materia correspondiente ofrece una declaración de seguridad y certeza". ${ }^{36}$

Los requisitos de esta son: 1) Exista un fallo de un órgano jurisdiccional; 2) Halla operado el principio de preclusión sobre la capacidad de impugnar; 3) Exista un pronunciamiento sobre el fondo y en forma cuando tenga efecto de perentorio complejo; 4) Que mantenga una observancia fiel y tributaria a los precedentes vinculantes, normatividad e interpretaciones

33 Sentencia del Tribunal Constitucional en el Expediente No. 04909-2007-HC.

34 Artículo 48.- La sentencia expedida por el Pleno se convierte en tal al ser firmada por el número minimo de Magistrados exigido por la ley. En el caso de la expedida por las Salas, debe contar con tres votos conformes. Sus efectos empiezan a regir desde el día siguiente a su notificación y, en su caso, publicación en el diario oficial El Peruano. La parte resolutiva de las sentencias en los procesos que declaran fundada total o parcialmente, la demanda de inconstitucionalidad de una ley, debe ser difundida, además, en dos diarios de circulación nacional.

35 Esta figura enteramente juridica nació en el proceso romano. Se ideó que la pretensión de una parte, el derecho material en el proceso, al entrar a ser discutida se transformaba en acción. Es decir, mutaba jurídicamente de ser material a ser meramente procesal. Es así que, al perder la causa, el derecho -la acción-'fallecía' con la derrota literalmente, es decir, no había forma de reabrir el caso-. La acción que fue res in juditio (cosa en proceso), pasa a ser res iudicata (cosa juzgada). Es así que surge el efecto de la cosa juzgada, en tanto, era una suerte peso que caiga sobre la acción. En tiempos modernos, la cosa juzgada es una autoridad impuesta por el ordenamiento de naturaleza distinta a su origen clásico, en el sentido que los derechos materiales no se transforman en procesales, sino que para nosotros la acción es autónoma, dato a considerar en la problemática abordada en el presente.

36 GARCIA TOMA, Víctor, Ob. Cit., p. 624. 
doctrinarias del Tribunal; 5) No exista fraude en la sentencia y se haya respetado en este la tutela procesal efectiva.

Es decir, para que exista cosa juzgada debe haber condiciones suficientes como para declarar satisfecho el interés procesal de las partes, es decir, que el resultado haya sido una producción real y total del Tribunal: una sentencia.

Siguiendo al propio TC, este a referido sobre la cosa juzgada que"la Constitución garantiza, a través de su artículo 139, inciso 2, es la cosa juzgada constitucional, la que se configura con aquella sentencia que se pronuncia sobre el fondo de la controversia juridica, de conformidad con el orden objetivo de valores, con los principios constitucionales y con los derechos fundamentales, y de acuerdo con la interpretación que haya realizado el Tribunal Constitucional de las leyes, o de toda norma con rango de ley, o de los reglamentos y de sus precedentes vinculantes, como lo prescriben los artículos VI y VII del Título Preliminar del Código Procesal Constitucional, respectivamente (...)". ${ }^{37}$

Los efectos de la cosa juzgada sobre la pretensión son los siguientes ${ }^{38}:$ 1) La declaración constatada de respeto pleno a los principios, valores y derechos constitucionales; 2 ) El respeto corroborado a la jurisprudencia y precedente vinculantes; 3 ) La inimpugnabilidad e imposibilidad de ulterior revisión o reexamen judicial; 4) La inmutabilidad e imposibilidad de ulterior modificación. Dicha condición es extensible al propio órgano jurisdiccional que dio la sentencia; 5) La inexorabilidad del cumplimiento de las consecuencias jurídicas determinadas en la sentencia.

Es aquí donde encontramos el fundamento a la premisa inicial: dictada la sentencia con efecto de cosa juzgada, esta debe ser procedida a ser ejecutada. Satisfecho el interés procesal, debiera procederse a satisfacer el derecho material. Surgida la complicación del incumplimiento, se revela de forma omisiva la prolongación innecesaria del proceso, al punto de persistir con la afectación y generar una nueva con la indebida demora. No solo se reconoce jurisdiccionalmente un derecho que es dejado en el vacío con su aún inconclusa promoción, sino que también se daña un nuevo derecho.

La sentencia es una expresión del concepto de lo justo por parte de los juzgadores que debe encontrar sus sustentos en el mundo jurídico que se concreta un documento.P.ero, esto no tiene real sentido y lógica si es que la función jurisdiccional del Estado no va tener impacto sobre la sociedad, entender al proceso como mera formalidad parte de un error, pues no esta considerando el impacto que tiene sobre lo que se mencione en un papel. Tratándose de la jurisprudencia del Tribunal, con mayor motivo se puede afirmar que un caso no termina hasta el momento en que se cumpla lo fallado.

Quien esta para servirse es el ciudadano, porque por ello tiene derechos, para eso acude al sistema de justicia y porque el Estado ha sido diseñado para ello. Debe entenderse, entonces, que el administrado no tiene ni debe ser perjudicado en la búsqueda de tutela efectiva. Es por ello que hemos de estar de acuerdo con Francisco Chamorro cuando expone sobre el derecho a obtener una compensación por el daño sufrido, en el caso de no poder llevar a cabo la sentencia. Señala que "la tutela judicial, para ser efectiva y no retórica, debe compensar al ciudadano si el cumplimiento de la sentencia no puede ser completo y eficaz. Ese es el derecho que constitucionaliza el TC (español) y que no se refiere, sin embargo, a los daños y perjuicios que sean consecuencia de una infracción o incumpli-

37 Sentencia del Tribunal Constitucional en el Expediente No. 00006-2006-CC.

38 GARCIA TOMA, Víctor, LoC. Cit. 
miento de parte y que pudieron solicitarse dentro del procedimiento".39

\section{MECANISMOS PARA GARANTIZAR EL CUMPLIMIENTO DE SENTENCIAS EN EL MARCO NORMATIVO NACIONAL}

Empecemos tratando sobre quién recae la responsabilidad de asegurar el cumplimiento de los mandatos ordenados por organismos constitucionalmente autónomos: El Artículo 118 de la Constitución reza de la siguiente manera: "Corresponde al Presidente de la República: 9.Cumplir y hacer cumplir las sentencias y resoluciones de los órganos jurisdiccionales."

El constituyente ha decidido que quien, en última cuenta, genere las condiciones y sea el principal interesado además de la parte y el Tribunal en que se cumpla una sentencia sea el Presidente de la República. Esta idea va de la mano con lo señalado en líneas anteriores, el problema discutido no es de simple incumbencia de un solo Poder del Estado o de entre partes, es un tema que involucra toda la maquinaria del Estado en sinergia de funciones.

De momento se nos ocurre pensar en el juez constitucional quien debe tener alguna forma de involucrarse. Pues, de hecho, así es. Leamos lo que expresa el TC:" eljuezconstitucional, tanto durante el desarrollo del proceso como en la tapa de ejecución está en la obligación de verificar que los abogados de las partes cumplan los deberes establecidos en el artículo 109 del Código Procesal Civil, en especial el establecido en el numeral 6), a efectos de colaborar con la etapa de ejecución de las sentencias. Asimismo, deben ejecutar los actos que permitan determinar la responsabilidad patrimonial de estos, conforme lo establece el artículo 110 de la norma precitada. Y, principalmente, en lo que corresponde a la responsabilidad de los letrados, cuando su conducta no sea contraria a los fines del proceso, por actuar con temeridad o mala fe, debe hacer de conocimiento de las instancias pertinentes tales hechos, conforme se establece en los artículos 111 y 112 del mismo Código".40

Legislativamente, existen los artículos 22 y 59 en el Código Procesal Constitucional que tratan sobre el cumplimiento de sentencias, procedamos a su tratamiento: el primero esta redactado de forma que es clara la intención en que exista un cumplimiento especifico de la sentencia, esto es, que se ejecute en sus propios términos siendo ilícito cualquier forma de sustitución de la sentencia. ${ }^{41}$ Adicional a esto, el mencionado prevé el uso de medidas coercitivas a ser recurridas una vez culminado el plazo de cumplimiento para asegurar la ejecución. ${ }^{42}$ Estas no son de uso forzoso a requerimiento de la parte ganadora, quien las puede exigir, sino que han sido dejadas al criterio del juzgador para su imposición, es decir, son dadas de oficio conforme al artículo 53 del Código adjetivo constitucional.

39 CHAMORRO, Francisco, Ob. Cit., p. 310, Hace esta reflexión refiriéndose a las sentencias del Tribunal Constitucional Español No. 32/1982 de 7 de junio y 26/2983 del 13 de abril que rezan "para el solicitante de amparo, el articulo 24 de.1 comprende el derecho a resarcirse de los perjuicios que le fueron ocasionados por la decisión del INSALUD de no incorporarle a su plaza de celador una vez concluidas y superadas las pruebas selectivas convocadas al efecto."

40 Sentencia del Tribunal Constitucional en el Expediente No. 4119-2005-AA.

41 Sobre este punto, no han faltado las voces discrepantes que abogan por la posibilidad de un pago de indemnización como sustición a lo dictaminado, esto basado en la naturaleza de las reparaciones, en tanto, el pago lo que pretende es hacer desaparecer los efectos del daño. Es recomendable CANALES, Carolina, Ob. Cit., pp. 45-61.

42 GARCIA TOMA, Víctor, Algunos alcances sobre la labor del Tribunal Constitucional, Ob. Cit., p. 39, a la pregunta sobre si esta de acuerdo con que es necesario que todas las sentencias deban incluir medidas coercitivas para asegurar el cumplimiento respondió "creo que una opción seria disponer en la ejecución de la decisión adoptada por el órgano jurisdiccional un conjunto de prescripciones en calidad de condicionales y en reserva, en donde se establezcan las medidas efectivas de sanción. En ese contexto, al fijarse de antemano un cronograma de actuaciones ejecutoriadas, consignarse el monto de las multas a aplicarse, etc. Podria intimidar más intensamente a los renuentes; o en su defecto aceleraría la consecución del pleno cumplimiento de sentencias, via aplicación de medidas coercitivas". 
Por ultimo, de persistir la inejecución es previsto que el funcionario responsable pueda ser destituido como sanción por la afectación.

El artículo 22 debe ser leído conjuntamente con el artículo 59. Este regula los plazos de ejecución y dispone que en caso de que el obligado no haya cumplido con lo sentenciado, el juez deberá llevar el proceso al superior del responsable a que lo haga cumplir y en caso habrá proceso administrativo contra el incumplidor. Y en el caso de que sea un funcionario público quien debe cumplir, el juez está facultado para expedir una sentencia ampliatoria que sustituya la omisión del funcionario y regule la situación conforme al sentido de la decisión.

Antes de proseguir, es imperativo hacer una breve mención al anterior cuerpo normativo precedente del Código Procesal Constitucional a fin de hacer una comparación de métodos. En la Ley 23506, de Hábeas Corpus y Amparo, existía la carencia de articulados específicos sobre ejecución, por lo que resalta de inicio la mejora legislativa. En su ley complementaria, la Ley 25398 , siendo evidente el vacío de urgente requerimiento, se señala en su artículo 27 que "las resoluciones finales consentidas o ejecutoriadas que recaigan en las acciones de garantía, serán ejecutadas por el juez, sala o tribunal que las conoció en Primera Instancia", y el artículo 28 que "en los casos de omisión por acto debido se notificará al responsable de la agresión concediéndole para su cumplimiento el término de 24 horas, tratándose de derechos protegidos por la acción de Hábeas Corpus y de 10 días calendario tratándose de derechos protegidos por la acción de Amparo y siempre que el término no perjudique el ejercicio del derecho reconocido por la resolución final (...) asimismo, se hará responsable del pago de los daños y perjuicios que resultaren de este incumplimiento". Como es evidente, se ha pasado de una posición pasiva a una activa, en tanto, ahora se puede velar por la ejecución aún contra el mismo juez cuando este sea el causante del daño. No solo quien sea renuente asume los costos adicionales que genere, sino que se le puede sancionar con multas fijas y acumulativas su omisión. Estamos, por tanto, en un mejor escenario.

Por otra parte, conjuntamente a los artículos 22 y 59 cuenta la ciudadanía (y el magisterio) con un trípode de principios ${ }^{43}$ sustentadores de la tutela efectiva que pueden y han de ser empleados para proteger la efectividad:

- Principio Pro actione: estipulado normativamente en el artículo 45 del Código adjetivo que se resume en lo literal afirmándose que en caso de duda de si proceder o no con el trámite a un proceso, siempre debe abrirse. La razón teleológica de este principio radica en que el juzgador no debe escatimar esfuerzos en llevar a proceso causas relevantes a violaciones de derechos fundamentales $y$ que estos no queden estériles, sino que sea real, es decir, eficaz.

De este principio se derivan otro también necesario para preservar la tutela efectiva: el antiformalismo o principio de elasticidad, el cual consiste en dejar de aplicar una norma procesal cuando esta entorpezca el proceso, para nuestro caso, cuando atente en fase de ejecución la finalidad de la misma. Sobre esto, se explaya Chamorro afirmando que "el formalismo consiste en confundir el instrumento con su finalidad porque "los presupuestos y requisitos que las leyes exijan han de ser valorados en su sentido y finalidad, es decir, mediante la razonable apreciación del medio en que consisten y del fin que con el se persigue medidos en su justa proporción y ello para evitar la preponderancia de lo que es solo instrumento entendido literalmente, con

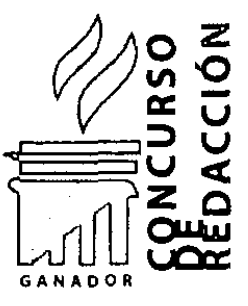

43 Principios constitucionales son "aquellas proposiciones o postulados con sentido y proyección normativa o deontológica vinculados a los procesos con vocación punitiva, que, por tales constituyen el núcleo central del sistema sancionador público o privado. Estos están destinados a asegurar la consagración y eficacia normativa de los valores y fines constitucionales, asi como la eficacia y eficiencia del corpus constitucional". Ver: GARCÍA TOMA, Víctor, Los Derechos Fundamentales en el Perú, Ob. Cit., p. 608. 
mengua de la finalidad ultima de la función judicial, no otra que la de resolver definitiva y eficazmente los conflictos que a ella se le someten'. Por su parte el antiformalismo no significa prescindir de las normas procesales, sino saber que parte de ellas es lo principal y que parte lo accidental". ${ }^{44}$ No se aboga por despreciar la norma, sino que se repudia al medio cuando se vuelve estorbo o traba y deja de ser conductor ordenador de las causas.

- Deber judicial de promover con la efectividad: Como se ha desarrollado a lo largo del presente, es clara la naturaleza de la función jurisdiccional del Estado y de la responsabilidad que tiene con la materialización de la tutela y de la acción activa que ha de tener a favor de esta.

- Principio de razonabilidad: Este sirve como control de la efectividad y del proceso mismo en su trámite y culminación. En efecto, puede afirmarse que es la última línea de defensa, en tanto, su tamiz si es bien desarrollado revelara si hubo o no una real tutela efectiva. No puede decirse que existe esta solo cuando se cumplen todas las leyes cuando de estas se produzcan sentencias absurdas que en vez de amparar derechos, consolidan y alargan situaciones de violación. Como es evidente, este principio va de la mano del primero desarrollado con el que, en causa común, pretenden lograr efectividad antes que una mera tutela formal o teórica.

Por otra parte, como acción activa a solucionar esta problemática, el Tribunal en la resolución del Expediente No. 0168-2007-Q/TC ha creado jurisdiccionalmente el Recurso de Agravio Constitucional a favor del cumplimiento de sus sentencias. Este mecanismo ha tenido que ser ingeniado, en tanto, el artículo 18 del Código adjetivo no lo prevé explícitamente.
Sin ánimo de entrar a analizar los detalles particulares del caso, entremos a ver lo creado ${ }^{45}$ :

Los supuestos previstos son los siguientes: 1) Incumplimiento imputable a un particular obligado. En caso de que la parte deudora se resista al cumplimiento y cuando persista aun a pesar de los requerimientos del juez y de las medidas coercitivas; 2 ) Incumplimiento imputable a un funcionario público; 3) Incumplimiento del juez. Esto, en tanto, sea el obligado a dar cumplimiento de la sentencia siendo parte perdedora y cuando no es parte, pero no cumple con exigir al perdedor el cumplimiento de su fallo.

Este redimensionamiento del RAC fue sustentado en los principios de economía procesal e informalismo con el propósito de proteger en específico el derecho a la eficacia de sentencias de órganos jurisdiccionales.

En breve, lo que se logra es que el TC resuelva en instancia final con el fin de restablecer el orden constitucional vulnerado con una inejecución, devolviendo todo lo actuado para que la instancia correspondiente de estricto cumplimiento a lo que determine. ${ }^{46}$

Es propio en este momento hacer mención a la respuesta del TC frente a esta problemática. En efecto, en la sentencia del Expediente No. 41192005-AA reconoce explícitamente la existencia de inejecuciones a sus fallos a la cual le decide dar frente doctrinariamente. Para empezar, verifica que existe en la realidad inejecución planteando un caso de frecuente repetición: la administración pública no cumple debido a una falta de presupuesto. Dicha sentencia hace referencia del Expediente No. 3149-2004-AC/ TC. Este trata de una acción de cumplimiento referida a la ejecución de una resolución administrativa que concluyó a favor del usuario, pero la administración si bien "no se mostraba

44 CHAMORRO, Francisco, Ob. Cit., p. 318.

45 Los párrafos siguientes se basan de RUIZ MOLLEDA, Juan Carlos, El nuevo recurso de agravio constitucional a favor del cumplimiento de sentencias del Tribunal Constitucional. En: Gaceta del Tribunal Constitucional, Gaceta Juridica, Tomo 4, Lima, Abril, 2008, pp. 65-81.

46 RUIZ MOLLEDA, Juan Carlos. Ob. Cit. Pág. 75. 
renuente", no cumplía con el pago que se había ordenado. Es cierto que este caso no concierne a una sentencia judicial, lo relevante es que en el análisis el Tribunal advirtió que se trataba de una actitud constante de la Administración respecto al pago de deudas dinerarias. ${ }^{47}$ En este caso, el TC advirtió que la mencionada "práctica constituye, además de un incumplimiento sistemático de las normas, una agresión reiterada a los derechos (...) No es admisible, e incluso carece de toda racionalidad, si se tiene en cuenta que es el propio Estado, a través del presupuesto público, quien solventa los gastos de procuradores y abogados (...) quienes en la mayoría de los casos, ante la irrefutabilidad de los hechos, se limitan a argumentar que "no existe presupuesto" o que, "teniendo toda la buena voluntad de cumplir con las resoluciones", no obstante, los beneficiarios "deben esperar la programación de parte del Ministerio de Economía y Finanzas".48

Existente la enfermedad, el TC trata de brindar al operador del derecho una suerte de catálogos de remedios..$^{49}$ Para empezar expresa que son mecanismos de cumplimiento de la sentencia constitucional y de "presión" los siguientes:

- La inmutabilidad de las decisiones del Tribunal Constitucional (artículo 121 del Código Procesal Constitucional).

- La competencia para la ejecución de las sentencias en los procesos constitucionales de la libertad está en manos del juez que recibió la demanda (artículo 22 del Código Procesal Constitucional).

- El principio de prevalencia de las sentencias constitucionales sobre cualquier otra decisión judicial. Esto tiene relevancia en el caso de decisiones que contienen condenas patrimoniales.
- El poder coercitivo de los jueces constitucionales incluye la posibilidad de ordenar el despido del funcionario que se resista al mandato contenido en una sentencia.

Por otra parte, citamos de la mencionada jurisprudencia las medidas que, para el TC, ha otorgado el Código Procesal Constitucional en cuanto a herramientas necesarias para que el juez ejecutor haga cumplir las sentencias emitidas en los procesos constitucionales, reglas que se detallan a continuación:

\section{Proceso constitucional de hábeas corpus:}

Dicha sentencia debe ser ejecutada en forma inmediata, independientemente del trámite de devolución de actuados al juez que conoció del proceso en primera instancia; en todo caso, corresponderá a este verificar el cumplimiento de la misma o, de ser el caso, ante el incumplimiento de ella, adoptar las medidas necesarias para la inmediata ejecución de lo ordenado. Cuando ello ocurra, el juez ejecutor debe adoptar las siguientes medidas:

- Poner en conocimiento del Ministerio Público el incumplimiento a fin de que dicha entidad formule la denuncia pertinente, por el delito contra la libertad individual, dado que la sentencia que ordena el cese de la medida que restringe el derecho a la libertad individual, es manifiestamente contraria a la Constitución, pues afecta el derecho fundamental a la libertad individual y/o conexos, de manera ilegítima y arbitraria. (tiene su sustento en el artículo 8 del Código Procesal Constitucional, el cual no solo debe interpretarse en el sentido de que, de existir no solo indicios de la comisión de un delito verificada durante la tramitación del hábeas

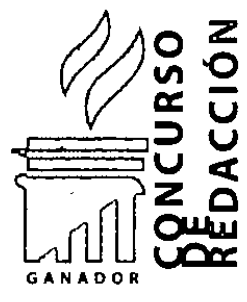

47 Sentencia del Tribunal Constitucional en el Expediente No 41 19-2005-AA.

48 Sentencia del Tribunal Constitucional en el Expediente No 3149-2004-AC.

49 Sentencia del Tribunal Constitucional en el Expediente No 4119-2005-AA. 
corpus, sino también durante la ejecución de la resolución recaída)

- Solicitar el apoyo de la fuerza pública para personalmente constituirse en el lugar donde se encuentra el agraviado en el proceso de hábeas corpus, con el objeto de proceder a ejecutar lo ordenado en la sentencia, en los términos previstos en ella (se sustenta en los artículos 118.9 y 166 de la Constitución, debido a que existe la obligación del Presidente de la República de cumplir y hacer cumplir las leyes, de donde se deriva que aquel debe prestar y disponer los recursos necesarios cuando sean requeridos por las autoridades jurisdiccionales; amén de que la Constitución prevé como finalidad fundamental de la Policía Nacional del Perú la de mantener y restablecer el orden interno, así como la de prestar protección y ayuda a las personas y a la comunidad, garantizando el cumplimiento de las leyes y la seguridad del patrimonio, por lo que le corresponde prevenir, investigar y combatir la delincuencia).

- Disponer la ejecución de medidas complementarias e idóneas para el cumplimiento de lo ordenado en la sentencia.

\section{Procesos constitucionales de amparo, hábeas data y cumplimiento:}

Por disposición de los artículos 65 y 74 del Código Procesal Constitucional, el procedimiento para la ejecución de las sentencias recaídas en los procesos de amparo también es aplicable al trámite de ejecución de sentencias que pongan fin a los procesos de hábeas data y cumplimiento, respectivamente.

La segunda sentencia que tenga que expedirse, sea integrando o complementando la decisión recaída en el proceso constitucional, corresponde al mismo órgano que emitió la sentencia materia de ejecución, sin distorsionar el sentido de la fundamentación y el fallo de la primera sentencia firme, de modo tal que, en caso de que aquella sea impugnada, le corresponderá resolver el recurso a la instancia jerárquicamente superior.
Distinto es el caso de una sentencia que haya sido expedida por el Tribunal Constitucional, dado que su decisión no puede ser objeto de recurso impugnativo alguno, por ser este órgano de control la última instancia en sede constitucional; en consecuencia, en este último supuesto, la decisión del Tribunal Constitucional, en caso de que se emita una nueva sentencia, deberá ser ejecutada en los términos que establezca el Supremo Intérprete de la Constitución.

Como es visto, existen las herramientas tanto para en condiciones regulares como para en caso de fallas en el sistema. Queda en manos de quienes corresponda el éxito de la tutela de derechos, llámese partes, magisterio o responsable de cumplir y hacer cumplir resoluciones.

Para la ejecución y culminación del proceso la función del Código Procesal Civil es supletoria. Si bien existe autonomía procesal para el TC, el cual puede y ha creado mecanismos procesales no previstos vía jurisprudencia, en aquellos aspectos no normados el Código adjetivo de lo civil es medio por el cual, como diría la teoría ferroviaria del derecho procesal, el tren que es la pretensión encuentra sus rieles nutridos culminantes para su satisfacción.

\section{MEDIDAS POSIBLES PARA FORTALECER LA EFECTIVIDAD}

Carolina Canales en su ya citado articulo publicado en la Gaceta del Tribunal Constitucional propone que se modifique la Ley Orgánica del TC de tal forma que sea este mismo por medio de un órgano quien esté encargado de adoptar las medidas necesarias para el cumplimiento de sus fallos que impongan obligaciones. Propone que pasado el plazo de ejecución sin cumplimiento, este Órgano ante la reticencia utilice los apremios de la vía ejecutiva como uso de la fuerza pública en pos de la eficacia.

Por otra parte, propone también, con acierto, dotar de mayores garantías al actual proceso de ejecución de sentencias del TC, considerando de vital importancia el "permitir que el favorecido con la sentencia fundada en los procesos de tutela 
de derechos fundamentales, se encuentre no solo legitimado para intervenir en el proceso de ejecución, sino dotarlo de las acciones y lo recursos necesarios para garantizar la plena reparación de sus derechos fundamentales".50

Desde otra arista, García Toma es de la idea que se "debiera dictar una norma especial en donde se establezcan de manera detallada y precisa las responsabilidades del Ministerio de Justicia como nexo intercomunicante entre el Poder Ejecutivo $y$ los órganos jurisdiccionales en lo relativo al cumplimiento de las sentencias. Mediante esta norma se coadyuvaría, propiciaría y compelería a que las distintas reparticiones del Poder Ejecutivo adecúen su conducta funcional a las determinaciones judiciales. Ello sería importante en relación a sectores tales como Interior, Defensa, salud; o a dependencias como la ONP".51

Referente imprescindible: la Corte Interamericana y la ejecución de sus sentencias

El artículo 25 de la Carta Americana de Derechos Humanos ${ }^{52}$, obliga a los Estados a no solo garantizar autoridades y mecanismos accesibles para acceder a una jurisdicción, sino que, como parte de una trinidad doctrinaria, incluye el aseguramiento del cumplimiento de lo que resulte del proceso. De este artículo podemos concluir dos cosas: que de acuerdo al principio del pacta sunt servanda ${ }^{53}$, al margen de la situación del derecho interno, es deber de nuestro país el cumplir y hacer cumplir la eficacia de lo que genere sus tribunales y lo dictaminado por la Corte IDH. Y lo segundo es que el círculo del acceso a la justicia empieza por la existencia de vías reales para poder gozar de tutela judicial, continua con tener mecanismos eficientes y no limitativos ni excluyentes y se cierra con la eficacia de las sentencias que resuelven el fondo de la pretensión. En concordancia con esto último, este fuero se expresó diciendo que "la responsabilidad estatal no termina cuando las autoridades competentes emiten la decisión o sentencia. Se requiere, además, que el Estado garantice los medios para ejecutar dichas decisiones definitivas".54

Desde nuestro ordenamiento, la ejecución de las sentencias emitidas por Tribunales Supranacionales están reguladas por la Ley 27775 , la cual en su primer artículo señala que es "de interés nacional el cumplimiento de las sentencias dictadas en los procesos seguidos contra el Estado Peruano por Tribunales Internacionales constituidos por Tratados que han sido ratificados por el Perú". Previendo el mecanismo siguiente para

50 CANALES, Carolina, Ob. Cit., p. 61

51 GARCIA TOMA, Victor, Ob. Cit.

52 Artículo 25. Protección Judicial

1. Toda persona tiene derecho a un recurso sencillo y rápido o a cualquier otro recurso efectivo ante los jueces o tribunales competentes, que la ampare contra actos que violen sus derechos fundamentales reconocidos por la Constitución, la ley o la presente Convención, aun cuando tal violación sea cometida por personas que actúen en ejercicio de sus funciones oficiales.

2. Los Estados partes se comprometen:

a. A garantizar que la autoridad competente prevista por el sistema legal del Estado decidirá sobre los derechos de toda persona que interponga tal recurso:

b. A desarrollar las posibilidades de recurso judicial, y

c. A garantizar el cumplimiento, por las autoridades competentes, de toda decisión en que se haya estimado procedente el recurso.

53 Este reza que los acuerdos deben cumplirse conforme a lo enunciado en ellos.

54 Ver: Caso Herrera Ulloa Vs. Costa Rica. Excepciones Preliminares, Fondo, Reparaciones y Costas. Sentencia de 2 de julio de 2004. Serie C No. 107, párr. 145; Caso Baena Ricardo y otros Vs. Panama. Competencia. Sentencia de 28 de noviembre de 2003. Serie C No. 104, párr., 79; Caso Cantos Vs. Argentina. Fondo; Caso de la Comunidad Mayagna (Sumo) Awas Tingni Vs. Nicaragua. Fondo, Reparaciones y Costas. Sentencia de 31 de agosto de 2001, Serie C No. 79 párr., 135; Caso Acevedo Jaramillo y otros. Fondo párr. 216 
su ejecución en caso de condena de pago de suma de dinero como indemnización por daños y perjuicios a cargo del Estado o sean meramente declarativas: el Ministerio de Relaciones Exteriores transcribe la sentencia al presidente de la Corte Suprema quien está encargado de remitirla a la sala que agotó la vía interna, teniendo 10 días como plazo para pago ordenado en caso de ser en tal sentido el fallo.

Por su parte a los jueces de la Corte IDH, siguiendo el artículo $16^{55}$ del reglamento de fuero, les corresponde llevar seguimientos periódicos de supervisión de la ejecución de sus sentencias. A diferencia de nuestro TC que asume por obligación legislativa una conducta pasiva tras haberse pronunciado, la Corte IDH nunca deja de lado sus casos, sino que continúa con ellos. Esto debido a que tienen bien claro que un caso no se puede declarar cerrado hasta que se cumpla su sentencia.

Cabe mencionar que las sentencias de la Corte IDH son de carácter obligatorio, pero no son ejecutivas, esto principalmente a dos motivos: "de acuerdo con la teoría general del Derecho debe haber una distinción entre el papel del juez y el del agente ejecutivo, y como en la sociedad internacional no existe un poder ejecutivo centralizado, no pueden darse potestades ejecutivas a los jueces. La segunda (...) si se considera que la limitación de la libertad de los Estados, operada por la suscripción de un compromiso internacional debe ser interpretada restrictivamente, cabría concluir que debería dejarse a los Estados un poder discrecional en cuanto a los medios disponibles para asegurar la ejecución de la sentencia". ${ }^{\prime 6}$ De este modo se hace comprensible la idea que las obligaciones de los Estados son de resultado y que, por ende, una inejecución de una sentencia de la Corte IDH venga a ser una violación de una obligación internacional.

Para los efectos, la eficacia solo se puede valorar por la posibilidad real existente por parte de los Estados para que garantice al lesionado su justa reparación u actuación estatal en caso que se ordenase..$^{57} \mathrm{El}$ proceso de ejecución es bien resumido por la doctrina que vengo siguiendo: "la Convención hace una remisión expresa directa al derecho interno para que, sin necesidad de tener que crear una ley procesal especial, se ejecute el fallo indemnizatorio emitido. Si bien es cierto que las legislaciones procesales internas suelen indicar expresamente cuales son las sentencias o documentos con carácter ejecutivo, es lo cierto que la Convención, una vez que ha sido ratificada, tiene la virtud de convertirse en Derecho Interno exigible"..$^{8}$ Para nuestro caso, contamos con una ley especial descrita líneas arriba para dar efecto a las sentencias.

\section{v. REFLEXIÓN FINAL}

Analizado todo lo previo es correcto afirmar que la naturaleza de la ejecución coincide plenamente con la del proceso mismo, siendo la

\section{Articulo 16.}

1. Los jueces cuyo mandato se haya vencido continuarán conociendo de los casos de los que ya hubieren tomado conocimiento y se encuentren en estado de sentencia. Sin embargo, en caso de fallecimiento, renuncia, impedimento, excusa o inhabilitación, se proveerá a la sustitución del juez de que se trate por el juez que haya sido elegido en su lugar si fuere este el caso, o por el juez que tenga precedencia entre los nuevos jueces elegidos en la oportunidad en que se venció el mandato del que debe ser sustituido.

2. Todo lo relativo a las reparaciones y costas, así como a la supervisión del cumplimiento de las sentencias de la Corte, compete a los jueces que la integren en este estado del proceso, salvo que ya hubiere tenido lugar una audiencia pública y en tal caso conocerán los jueces que hubieren estado presentes en esa audiencia.

3. Todo lo relativo a las medidas provisionales compete a la Corte en funciones, integrada por Jueces Titulares.

56 RODRIGUEZ, Victor Manuel, Ejecución de sentencia de la corte. En: El futuro del Sistema Interamericano de Protección de Derechos Humanos, p. 445.

57 En el Caso Loayza Tamayo se ordenó su liberación, siendo el primer caso de restitución plena

58 RODIGUEZ, Victor Manuel, Ob. Cit., p. 465. 
esencia la razón de ser y por ende la finalidad en sí. Volver al estado anterior de una violación a un derecho fundamental no es otra cosa que desagraviar a la persona, demostrarle que existe un ordenamiento con el único propósito de ampararle cuando es violentado. Es aquí donde radica la gravedad de la inejecución, pues tiene en símisma cargada la pulpa de la arbitrariedad.

Una sentencia del TC es la Constitución viva, son la voz directa y autentica del proyecto de sociedad ideado por los representantes con Poder originario. Dejar sin consecuencias reales a la Constitución viva es no solo denigrarle sino también a la sociedad misma. Los derechos son parte del hombre, el ser humano es en sí mismo por su naturaleza gregaria y cooperativa derecho en sí mismo. Que estén redactados en el artículo 2 como catálogo, no es reducir al hombre a una formula averiguable sino que tenerlos escrito es un reconocimiento a que no solo son individuales sino que los derechos subjetivos son parte de la colectividad.
Tanto el observador como el usuario del fuero constitucional deben sentirse en todo momento que está siendo resguardado, no se puede sumir al necesitado de justicia en la más absoluta inseguridad jurídica de litigar por una sentencia que venga a ser letra muerta en materia de ejecución. Como reza el principio chiovendiano "la necesidad del proceso para obtener la razón no debe convertirse en un daño para el que tiene la razón", la litis es instrumento para obtener acción, no debe volverse mecanismo de obstrucción.

El incentivo social producido ante una sentencia que nunca se cumple, ante la demostración de que el sistema en sí mismo puede llegar a ser una falacia y ante el desamparo del hombre por la formalidad, lo que se está haciendo es destruir a lo que significa ciudadanía y evitando la enseñanza de esta, siendo los responsables autores directos de la profundización, perpeturización y expansión de la denominada pobreza legal.

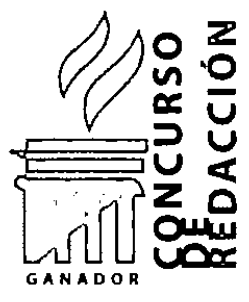

